\title{
Biliary Colic is a Valuable Clinical Descriptor for Biliary Pain Due to "Uncomplicated" Gallstone Disease
}

\author{
Marc G. H. Besselink • Karel J. van Erpecum
}

Received: 21 April 2009 / Accepted: 3 June 2009 /Published online: 23 June 2009

(C) The Author(s) 2009. This article is published with open access at Springerlink.com

We thank Drs Oria and Kohan for their interesting comments on our article: "Is complicated gallstone disease preceded by biliary colic?"1 We found that $57 \%$ of 175 patients with complicated gallstone disease (including pancreatitis) had experienced biliary colics before the complication. In these cases, the complication could probably have been prevented by early cholecystectomy. However, significant patient's and general practitioner's delays had occurred after the "warning" colic (especially if the pain was located in the epigastric region), thus precluding this option in practice. We agree with Drs Oria and Kohan that it is not possible to differentiate between biliary colic due to cystic duct obstruction by gallbladder stones and biliary colic caused by stones migrated to the bile duct. In fact, the term "biliary colic" does not pretend to make such differentiation. Although considered "a confounding term" by the authors, "biliary colic" is used frequently to describe biliary pain due to "uncomplicated gallstone disease," not only by this journal ${ }^{2}$ but also by other key journals ${ }^{3,4}$ and the Cochrane database. ${ }^{5}$

Nevertheless, the "a priori" chance that gallbladder stones are the cause of biliary colic is much higher than bile duct stones, provided that significant abnormalities in liver biochemistry and clear bile duct dilatation by ultrasound are absent. Indeed, most episodes of biliary colic resolve spontaneously, without subsequent complications. Using various techniques including routine intraoperative cholangiography during cholecystectomy, frequency of unexpected bile duct stones in patients who have experienced biliary colics varies between $5 \%$ and

M. G. H. Besselink $(\bowtie) \cdot$ K. J. van Erpecum

University Medical Center Utrecht,

Utrecht, The Netherlands

e-mail: m.besselink@umcutrecht.nl
$12 \%{ }^{6,7}$ These data indicate that bile duct stones are relatively rare in patients with biliary colics and/or that most bile duct stones migrate spontaneously to the duodenum. Oria and Kohan report interesting data on migration of bile duct stones in 39 patients with prior biliary pain, using the time-honored technique of stool screening. ${ }^{8-10}$ In fact, their patients all had dilated bile ducts by ultrasound and may thus not be entirely representative of the entire population of patients with biliary colics. In addition, there is no solid evidence that early detection or bile duct stones by endoscopic ultrasound or magnetic resonance cholangiopancreatography would lead to a more beneficial outcome in the entire group of patients who have experienced biliary colics. If one assumes an a priori chance of $5 \%$ for bile duct stones under these circumstances and endoscopic ultrasound to have a sensitivity and specificity of $95 \%$, positive predictive value of finding bile duct stones by endoscopic ultrasound would be only $50 \%$. Subsequent endoscopic retrograde cholangiopancreatography would thus expose $50 \%$ of the patients to unnecessary risks of this procedure. In addition, the natural history of bile duct stones under these circumstances is uncertain. ${ }^{6,7}$

The authors further state that "in order to prevent acute gallstone pancreatitis, early identification of patients undergoing anicteric episodes of gallstone migration is essential." However, the evidence for this statement is lacking. No study has shown a reduction in incidence of biliary pancreatitis by differentiating between cystic and main duct obstruction. In our opinion, additional investigations and treatment of bile duct stones in patients with biliary colics should be performed depending on the chance that bile duct stones are indeed present (for useful risk factors see Abboud et al. ${ }^{11}$ ) In contrast, as we conclude in our paper, a policy of 
timely referral and cholecystectomy of patients with biliary colic could prevent complicated gallstone disease, including biliary pancreatitis in up to $50 \%$ of cases.

Open Access This article is distributed under the terms of the Creative Commons Attribution Noncommercial License which permits any noncommercial use, distribution, and reproduction in any medium, provided the original author(s) and source are credited.

\section{References}

1. Besselink MG, Venneman NG, Go PM, Broeders IA, Siersema $\mathrm{PD}$, Gooszen $\mathrm{HG}$, et al. Is complicated gallstone disease preceded by biliary colic? J Gastrointest Surg 2009;13:312-317. doi:10.1007/s11605-008-0729-y.

2. Pratt JS, Van NM, Christison-Lagay E. The tethered bezoar as a delayed complication of laparoscopic Roux-en-Y gastric bypass: a case report. J Gastrointest Surg 2007;11:690-692. doi:10.1007/ s11605-007-0098-y.

3. Aggarwal R, Grantcharov T, Moorthy K, Milland T, Darzi A. Toward feasible, valid, and reliable video-based assessments of technical surgical skills in the operating room. Ann Surg 2008;247:372-379. doi:10.1097/SLA.0b013e318160b 371.
4. Zaliekas J, Munson JL. Complications of gallstones: the Mirizzi syndrome, gallstone ileus, gallstone pancreatitis, complications of "lost" gallstones. Surg Clin North Am 2008;88:1345-1368. doi:10.1016/j.suc.2008.07.011.

5. Gurusamy KS, Samraj K, Fusai G, Davidson BR. Early versus delayed laparoscopic cholecystectomy for biliary colic. Cochrane Database Syst Rev 2008;(4):CD007196.

6. Murison MS, Gartell PC, McGinn FP. Does selective peroperative cholangiography result in missed common bile duct stones? J R Coll Surg Edinb 1993;38:220-224.

7. Caddy GR, Tham TC. Gallstone disease: Symptoms, diagnosis and endoscopic management of common bile duct stones. Best Pract Res Clin Gastroenterol. 2006;20:1085-1101. doi:10.1016/j. bpg.2006.03.002.

8. Oria A, Kohan G. Letter: Biliary colic preceding acute gallstone pancreatitis. J Gastrointest Surg 2009; in press.

9. Oria A, Frider B, Alvarez J, Chiappetta L, Souto N, Fontana JJ. Biliary and pancreatic obstruction during gallstone migration. Int $\mathrm{J}$ Pancreatol 1988;3:157-164.

10. Oria A, Alvarez J, Chiapetta L, Fontana JJ, Iovaldi M, Paladino A, et al. Risk factors for acute pancreatitis in patients with migrating gallstones. Arch Surg 1989;124:1295-1296.

11. Abboud PA, Malet PF, Berlin JA, Staroscik R, Cabana MD, Clarke JR, et al. Predictors of common bile duct stones prior to cholecystectomy: a meta-analysis. Gastrointest Endosc 1996;44:450-455. doi:10.1016/S0016-5107(96)70098-6. 